\title{
Internal thoracic artery grafting in the elderly and the challenge to conventional wisdom
}

\author{
Paul Kurlansky, MD
}

\author{
From the Department of Surgery, Columbia University, New York, NY. \\ Disclosures: Author has nothing to disclose with regard to commercial support. \\ Received for publication July 20, 2015; accepted for publication July 20, 2015. \\ Address for reprints: Paul Kurlansky, MD, Department of Surgery, Columbia University, Black Building 210, 650 \\ W 168th St, New York, NY 10032 (E-mail: pk2245@cumc.columbia.edu). \\ J Thorac Cardiovasc Surg 2015;150:900-1 \\ $0022-5223 / \$ 36.00$ \\ Copyright (c) 2015 by The American Association for Thoracic Surgery \\ http://dx.doi.org/10.1016/j.jtcvs.2015.07.062
}

When challenged by new information that questions conventional wisdom, one's knowledge base is likely best served by reexamining the evidence on which that "wisdom" is based, and then evaluating the data that might support a new perspective. It is just this circumstance that is presented by Singh and colleagues ${ }^{1}$ in their thought-provoking study in this issue of the Journal, which explores the impact of sex on long-term survival of coronary artery bypass surgery in octogenarians. On reviewing the outcomes of a robust series of 1141 octogenarian patients, these researchers discovered that the long-term survival benefit from the use of the internal thoracic artery (ITA) was seen in the female patients but not in the male patients.

Previous studies in elderly populations have documented a benefit of ITA grafting in both perioperative $e^{2,3}$ and longterm survival. ${ }^{4-6}$ In fact, review of Medicare data demonstrated a long-term survival benefit for ITA grafting that was seen in both men and women and persisted in the octogenarian population as late as the age of 86 years. ${ }^{6}$ Although octogenarian women do appear to have an enhanced long-term survival relative to men after coronary artery bypass grafting surgery, ${ }^{3}$ the delineation of the role of sex in determining prognosis for IMA grafting in the octogenarian population has not previously been well defined.

It is into this knowledge gap that Singh and colleagues ${ }^{1}$ have delved. Although it is theoretically possible that their results could be explained by an older male cohort (especially $>86$ years), we find an identical mean age for their male and female patients receiving ITA grafts (82.5 years). More careful examination of their data does, however, provide several alternative explanations for their findings. First, it should be noted that the study registry actually represents the merged data of 2 separate surgical teams at 2 separate institutions. Although there may be shared protocols and resources, the impact of differences in surgical selection and expertise, clinical care, and cardiology follow-up cannot be underestimated. Because the modeling of Singh and colleagues ${ }^{1}$ did not account for institutional or surgical

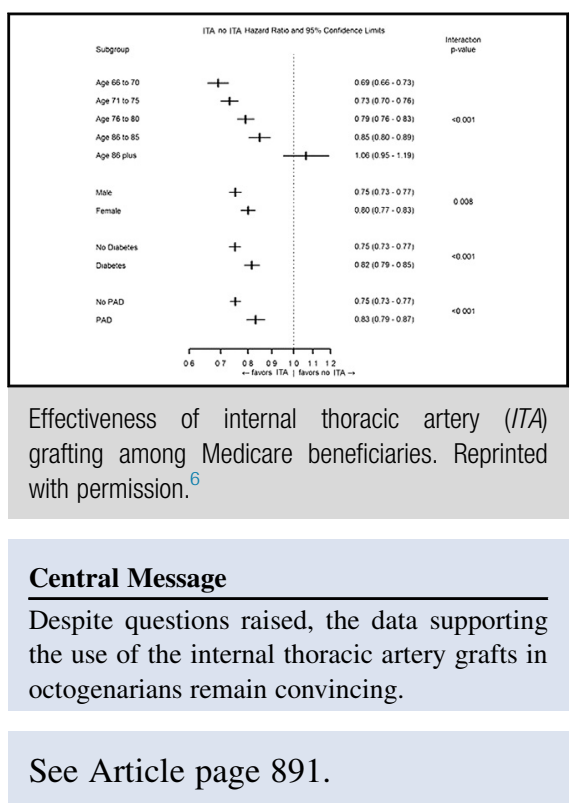

clustering, it is somewhat impossible to determine whether outcome is related to choice of conduit or to surgeon or institution.

Equally concerning is the reported risk adjustment using the Society of Thoracic Surgeons (STS) predicted risk of mortality. Authors report STS 30-day risks of mortality for patients receiving ITA grafts of $0.7 \%$ for both male and female patients, whereas the reported risks for patients receiving non-ITA grafts were $0.4 \%$ for men and $1.2 \%$ for women. Several points are worthy of note. First, this would seem to define a highly select group of patients. In addition, the figures themselves warrant some concern, because entry into the online STS risk calculator ${ }^{7}$ for a putative 82year-old male or female patient with a normal ejection fraction and no risk factors yields risks approximating twice those reported as mean for this study population. Could there have been multiple typographic errors or miscalculations? The actual reported mortalities were several times the reported STS risk and much more consistent with previous reports: $4.3 \%$ for male ITA recipients, $4.4 \%$ for female ITA recipients, $8.4 \%$ for male recipients of nonITA conduits, and $5.7 \%$ for female recipients of ITA conduits, with the absence of calculated statistical difference in observed mortality subject to the limitations of sample size. 
If, on the other hand, one were to accept the stated STS risk scores, one might actually predict the long-term outcomes observed. Although the STS risk score was developed as a prediction model for perioperative mortality, it has been shown to predict long-term survival as well. ${ }^{8}$ Because the predicted risk was higher for male patients receiving ITA conduits than for male patients receiving other conduits, the fact that long-term survivals were equivalent suggests a benefit for the use of the ITA. Similarly, because the risk was higher for female patients receiving other conduits than for female patients receiving ITA conduits, we should not be surprised that this ITA group had a better survival.

Survival, it must be remembered, is only one gauge of long-term outcome. In the very elderly population, survival differences may be limited. For many elderly patients, however, loss of independence or function is more frightening than loss of life itself. Surgical decision making must therefore be informed by a careful assessment of both prognosis and quality of life. ${ }^{9}$ Clearer definition of how ITA grafting might impact these more complex parameters is a topic ripe for more in-depth research.

Therefore, although conventional wisdom regarding the use of the ITA in octogenarian patients undergoing surgical revascularization clearly has room for challenge and better definition, it does not appear there are yet sufficient data to abandon, or even seriously question, the use of the ITA in our elderly male patients.

\section{References}

1. Singh AK, Maslow AD, Machan JT, Fingleton JG, Feng WC, Schwartz C, et al Long-term survival after use of internal thoracic artery in octogenarians is gender related. J Thorac Cardiovasc Surg. 2015;150:891-9.

2. Ferguson TB Jr, Coombs LP, Peterson ED. Internal thoracic artery grafting in the elderly patient undergoing coronary artery bypass grafting: room for process improvement? J Thorac Cardiovasc Surg. 2002;123:869-80.

3. Kurlansky PA, Williams DB, Traad EA, Zucker M, Ebra G. Eighteen-year followup demonstrates prolonged survival and enhanced quality of life for octogenarians after coronary artery bypass grafting. J Thorac Cardiovasc Surg. 2011;141:394-9. e1-3.

4. Moon MR, Sundt TM III, Pasque MK, Barner HB, Gay WA Jr, Damiano RJ Jr. Influence of internal mammary artery grafting and completeness of revascularization on long-term outcome in octogenarians. Ann Thorac Surg. 2001;72:2003-7.

5. Kurlansky PA, Williams DB, Traad EA, Carrillo RG, Schor JS, Zucker M, et al Arterial grafting results in reduced operative mortality and enhanced long-term quality of life in octogenarians. Ann Thorac Surg. 2003;76:418-26; discussion 427.

6. Hlatky MA, Boothroyd DB, Reitz BA, Shilane DA, Baker LC, Go AS. Adoption and effectiveness of internal mammary artery grafting in coronary artery bypass surgery among Medicare beneficiaries. J Am Coll Cardiol. 2014;63:33-9.

7. The Society of Thoracic Surgeons. Short-term risk calculator and models. Available at: http://www.sts.org/quality-research-patient-safety/quality/risk-calculatorand-models. Accessed July 20, 2015.

8. Puskas JD, Kilgo PD, Thourani VH, Lattouf OM, Chen E, Vega JD, et al. The Society of Thoracic Surgeons 30-day predicted risk of mortality score also predicts long-term survival. Ann Thorac Surg. 2012;93:26-33; discussion 33-5.

9. Gelsomino S, Lorusso R, Livi U, Masullo G, Lucà F, Maessen J, et al. Cost and cost-effectiveness of cardiac surgery in elderly patients. J Thorac Cardiovasc Surg. 2011;142:1062-73. 